\title{
Metastasis of lobular breast carcinoma diagnosed by rectal macrobiopsies
}

\author{
F. Macías-García, M. Sobrino-Faya, J. E. Domínguez-Muñoz \\ Gastroenterology Department and Foundation for Research in Digestive Diseases (FIENAD). University Hospital of \\ Santiago de Compostela. A Coruña, Spain
}

\section{CLINICAL CASE}

We present the case of a 72-year-old woman with invasive lobular breast carcinoma, stage IV (vertebral metastasis), and with recent-onset constipation. Digital rectal examination revealed increased consistency of the rectal wall. Laboratory test showed only elevation of CEA-II (28'3). Rectoscopy showed a partial stenosis of the rectal lumen, extending from the internal anal margin to about $10 \mathrm{~cm}$, with irregular and micronodular mucosa and clearly decreased rectal wall distensibility simulating linitis plastica (Fig. 1A). Biopsy revealed only chronic inflammatory changes. Endoscopic ultrasonography identified a diffuse thickening of the rectal wall, up to $13 \mathrm{~mm}$, with loss of normal echostructure. Further biopsies and fine-needle aspiration $(22 \mathrm{G})$ were performed without showing either the existence of atypical cells. Given the high suspicion of rectal metastatic disease, macrobiopsies with polipectomy snare were taken (Fig. 1B). Final histological diagnosis was metastatic carcinoma of the breast (stained positively for cytokeratin AE1, AE3, cytokeratin 19, mammaglobin, GCDFP-15 and estrogen receptors).

\section{DISCUSIÓN}

Metastases in the gastrointestinal tract are rare, being the breast cancer one of the most frequent origins (1), especially the invasive lobular carcinoma subtype (10-20\% of breast tumors). In the gastrointestinal tract is more common the gastric involvement, being the rectal involvement less frequent (2). The stiffness and diffuse thickening of the rectal wall may mimic linitis plastica. The possibility of rectal metastasis without hepatopulmonary metastasis may be explained by the
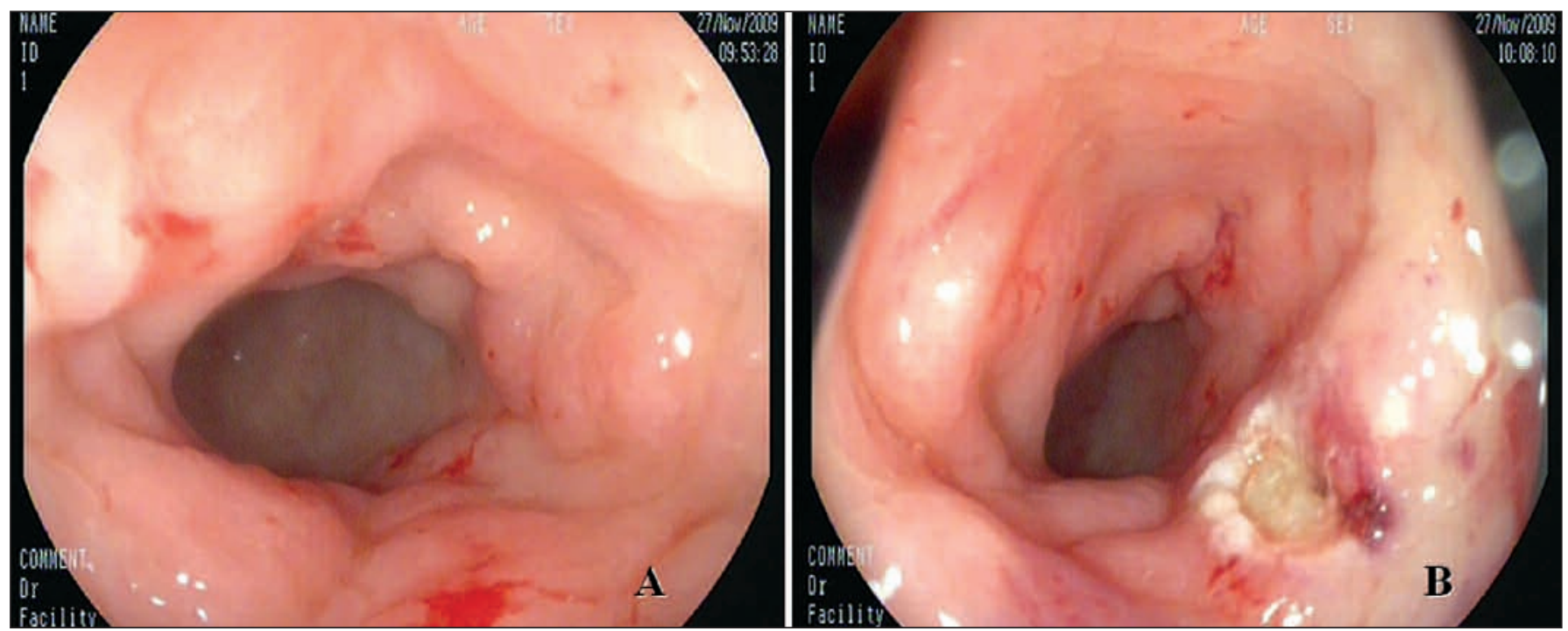

Fig. 1. A. Rectoscopy view showing a partial stenosis of the rectal lumen, with irregular and micronodular mucosa. B. Close-up view after macrobiopsy with polipectomy snare. 
existence of the vertebral venous plexus. Since tumor spread is hematogenous and epithelia are avascular, submucosal or subserosal involvement occurs firstly, extending to mucosa layer in final stages. This condition explains the high rate of false negative histological studies obtained by conventional endoscopic biopsy (3). In this sense, obtaining macrobiopsies with polipectomy snare or by EUS-guided FNA may help the diagnosis. Treatment of colorectal metastases is chemotherapy, reserving surgery for the treatment of complications such as perforation, bleeding or obstruction $(4,5)$.

\section{REFERENCES}

1. Bamias A, Baltayiannis G, Kamina S, Fatouros M, Lymperopoulos E, Agnanti N, et al. Rectal metastases from lobular carcinoma of the breast: Report of a case and literature review. Ann Oncol 2001; 12: 715-8.

2. Borst MJ, Ingold JA. Metastatic patterns of invasive lobular versus invasive ductal carcinoma of the breast. Surgery 1993; 114(4): 637-41.

3. Cano-Maldonado AJ, Díaz-Tie M, Vives-Rodríguez E, Lux KM, Basanta-Calderón Y, Alcázar-Montero JA, et al. Rectal metastasis of lobular breast carcinoma. Rev Esp Enferm Dig 2008; 100(7): 440-2.

4. Martínez Lesquereux L, Paredes Cotoré JP, Ladra González MJ, Beiras Torrado A. Colon metastasis of lobular breast cancer. Cir Esp 2010; 88: 122-4.

5. Jiménez Rodríguez RM, Galindo Galindo A, Bermejo Navas A, Bernardos García C, Sousa Vaquero JM, Palacios González C, et al. Small bowel obstruction caused by metastasis for lobulillar breast cáncer. Rev Esp Enferm Dig 2007; 99(5): 302-3. 